\title{
Hacia una pragmalingüistica integral: el caso de por fin como recurso de (des)cortesia en el discurso digital y político
}

\author{
Carlos meléndez Quero \\ Profesor Titular (Maître de conférences) de Español \\ ATILF, CNRS, Université de Lorraine \\ 44 avenue de la Libération \\ BP 30687 \\ 54063 Nancy Cedex (Francia) \\ E-mail: carlos.melendez@univ-lorraine.fr \\ 0033354505300
}

\begin{abstract}
HACIA UNA PRAGMALINGÜÍSTICA INTEGRAL: EL CASO DE POR FIN COMO RECURSO DE (DES)CORTESÍA EN EL DISCURSO DIGITAL Y POLÍTICO
\end{abstract}

RESUMEN: El objetivo de este artículo es el estudio de la locución por fin del español como mecanismo de (des)cortesia en el discurso persuasivo, con especial atención al discurso actual en Internet y al referido al ámbito político. Desde una perspectiva teórica próxima a la lingüistica pragmática descrita en Fuentes (2017[2000]), nos situamos en un marco metodológico que defiende una pragmalingüistica en la que convergen la teoria de la argumentación, la teoría polifónica de la enunciación y la cortesía verbal. Con este enfoque, esta investigación describe cómo el operador por fin tiene un significado polifónico que puede ser explotado en el discurso con fines argumentativos diversos en sus diferentes contextos de empleo. Para ilustrar nuestro análisis, nos servimos de un corpus de ejemplos reales, tomados del corpus digital Macrosintaxis del Español Actual (MEsA) y de documentos de temática política del CREA y del CORPES XXI

PALABRAS ClAVES: argumentación; enunciación; (des)cortesía pragmalingüistica; operadores.

SUMARIO: 1 . Introducción. 2. Corpus. 2.1. Materiales seleccionados 2.2. Representatividad de los operadores en el corpus. 3. Marco teóricometodológico. 4. Análisis de por fin. 5. Conclusiones.

\section{TOWARDS A COMPREHEN- SIVE PRAGMALINGUISTICS: THE CASE OF POR FIN AS A RESOURCE OF (IM)POLITE- NESS IN THE DIGITAL AND POLITICAL DISCOURSE}

ABSTRACT: The aim of this article is to study the Spanish locution por fin as a mechanism of (im)politeness in persuasive discourse, with special attention to current speech on the Internet and to discourse related to the political sphere. From a theoretical perspective close to the pragmatic linguistics described in Fuentes (2017 [2000]), we adopt a methodological framework that defends a pragmalinguistics where the theory of argumentation, the polyphonic theory of enunciation and verbal politeness converge. Within this approach, this research describes how the polyphonic meaning of the operator por fin can be exploited in discourse with different argumentative purposes in their various contextual uses. To illustrate our analysis, we use a corpus of real examples, taken from the digital corpus Macrosintaxis del Español Actual (MEsA) and from documents about politics of CREA and CORPES XXI.

KEY WORDS: argumentation; enunciation; (im)politeness; pragmalinguistics; operators.

SUMMARY: 1 . Introduction. 2 Corpus. 2.1. Selected materials. 2.2. Representativeness of the operators in the corpus. 3 . Theoretical-methodological framework. Analysis of por fin. 5. Conclusions.

\section{VERS UNE PRAGMALINGUISTIQUE INTEGRALE: LE CAS DE POR FIN COMME RESSOURCE D'(IM)POLITESSE DANS LE DISCOURS NUMERIQUE ET POLITIQUE}

RÉSUMÉ: L'objectif de cet article est d'étudier la locution por fin de l'espagnol en tant que mécanisme d'(im)politesse dans le discours persuasif, en portant une attention particulière au discours actuel sur Internet et à celui lié à la sphère politique. Dans une perspective théorique proche de la linguistique pragmatique décrite dans Fuentes (2017 [2000]), nous nous situons dans un cadre méthodologique qui soutient une pragmalinguistique dans laquelle convergent la théorie de l'argumentation, la theorie polyphonique de l'énonciation et la politesse verbale. Dans cette approche, cette recherche décrit la manière dont la signification polyphonique de l'opérateur por fin peut être exploitée au niveau discursif à des fins argumentatives variées dans ses différents contextes d'emploi. Afin d'illustrer notre analyse, nous nous servons d'un corpus d'exemples réels, tirés du corpus numérique Macrosintaxis del Español Actual (MEsA) et de documents du domaine politique du CREA et du CORPES XXI.

MOTS CLÉS: argumentation énonciation; (im)politesse; pragmalinguistique; opérateurs.

SOMMAIRE: 1 . Introduction. 2 Corpus. 2.1. Matériaux sélectionnés. 2.2. Représentativité des opérateurs dans le corpus. 3. Cadre théoricométhodologique. Analyse de por fin. 5. Conclusions.
Fecha de Recepción Fecha de Revisión Fecha de Aceptación Fecha de Publicación 


\title{
Hacia una pragmalingüistica integral: el caso de por fin como recurso de (des)cortesia en el discurso digital y politico
}

\author{
CARLOS MELÉNDEZ QUeRO
}

\section{INTRODUCCIÓN}

A partir del estudio del operador ${ }^{1}$ por fin en español actual, esta investigación pretende avanzar hacia una "pragmalingüística integral" (Fuentes, 2012: 49), haciendo hincapié en la relación entre emociones, argumentación, enunciación y estrategias de (des)cortesia.

Buscando contextos reales del empleo de por fin en el ámbito panhispánico, describiremos los corpus (MEsA, CORPES XXI y CREA) objeto de estudio (punto 2), justificando los motivos de su elección y ofreciendo datos comparativos de la frecuencia de este signo en relación con otros operadores del español que sirven para introducir evaluaciones subjetivas emotivas de orientación favorable o desfavorable.

Presentado el corpus, explicaremos el marco teórico-metodológico en el que se sitúa esta investigación (epígrafe 3), destacando, de una parte, la estrecha relación que existe entre la modalidad y la argumentación y, de otra, la importancia de conectar el análisis del significado del operador modal por fin con los fines argumentativos para los que puede emplearse en el nivel discursivo.

Partiendo de este enfoque, el apartado 4 de este artículo servirá para describir con ejemplos reales del corpus, cómo la información semántico-discursiva que está en la base del operador por fin permite explicar sus diferentes empleos y sus fines persuasivos.

\section{CORPUS}

En este apartado vamos a describir los corpus en los que nos hemos basado para contextualizar el empleo de por fin, así como para obtener datos empíricos de su utilización en discursos variados del español actual2.

\footnotetext{
${ }^{1}$ Nos servimos de este término, recogido en el diccionario de Fuentes (2009a: 270), al designar a por fin como operador modal. El concepto de operador está igualmente muy extendido en los trabajos del francés, como Anscombre et al. (2013), en el que se recurre a opérateurs discursifs para hacer referencia a signos discursivos entre los que se encuentra enfin, descritos en términos de operaciones semántico-pragmáticas que están en la base de diferentes estrategias enunciativas (sobre el concepto de opérateur, véase Vázquez, 2016).

Asimismo, este término convive con el de partículas, muy difundido en español y, en particular, en diccionarios especializados, como Santos (2003) o Briz et al. (2008), que incluyen, en su análisis, a por fin. Para una discusión terminológica sobre este concepto y su relación con otras etiquetas como la de marcadores del discurso, remitimos a Martín (2010).

2 Para Brenes (2014: 78), estas investigaciones sobre la (des)cortesía pueden completarse con estudios detallados "de los recursos lingüísticos empleados en su verbalización, así como con un análisis cuantitativo de estas estrategias que nos permita conocer su frecuencia de uso y,
} 


\subsection{MATERIALES SELECCIONADOS}

Para disponer de una muestra representativa del uso de por fin en el discurso persuasivo, hemos confrontado materiales lingüisticos de diferente naturaleza: por un lado, los recogidos en el corpus de fuentes digitales $M a-$ crosintaxis del Español Actual (MEsA) ${ }^{3}$ y, por otro lado, los extraidos de los bancos de datos sincrónicos de la Real Academia Española (CREA y CORPES XXI), con especial atención a los relacionados con el ámbito político ${ }^{4} \mathrm{y}$ limitados a documentos de este siglo 5 .

En primer lugar, la elección del corpus MEsA responde a un enfoque integrador y multidimensional por acercarnos al lenguaje digital actual recogido en diferentes medios de comunicación virtual (blogs, foros, páginas web, WhatsApp, Facebook, Instagram, Twitter y YouTube). Como se indica en la guía del corpus $\mathrm{MEsA}^{6}$, estos materiales permiten “acercarse a la comunicación verbal en Internet, poniendo especial foco en los textos escritos 7 (aunque no exclusivamente)" y favorecen "las comparaciones de resultados de distintas fuentes" del ámbito panhispánico, facilitando así el acceso a "las principales vías de comunicación de la sociedad actual"8 y a "fenómenos lingüisticos que no se encuentren con tanta frecuencia en corpus de textos escritos convencionales o de conversaciones transcritas" (Pérez, 2017: 2-3). En suma, este corpus MEsA permite estudiar el lenguaje en Internet, donde los usuarios, generalmente agresivos, suelen escudarse "en su identidad virtual para transgredir las normas sociales" (Padilla, 2015: 437), lo que facilita

por ende, su representatividad" en los discursos estudiados. Sobre la importancia de tomar como punto de partida muestras reales de discurso para el estudio de la (des)cortesía, véase también Bravo (2005).

3 Agradecemos a la profesora Fuentes el acceso a estos materiales, disponibles en: http://grupo.us.es/grupoapl/otrosapartados.php?otro=10 (Fecha de consulta: 05/02/2018). Sobre las características de este corpus en relación con el proyecto Macrosintaxis del Español Actual, véase Fuentes (2017).

${ }^{4}$ Aunque parezcan materiales de naturaleza diferente, el estudio de Kaul y Cordisco (2014: 158) permite advertir algunas semejanzas, al mostrar que, como sucede con el discurso político, el comportamiento descortés es el elemento no marcado en Internet en redes sociales.

${ }^{5}$ Los datos del CREA están disponibles en: http://corpus.rae.es/creanet.html (Fecha de consulta: 05/08/2018). Para el CORPES XXI, nos servimos de la versión 0.9, a fecha de 25/09/2018, que se puede consultar en: http://web.frl.es/CORPES/view/inicioExterno.view. 6 En: http://grupo.us.es/grupoapl/acceso/actividades/pdf/gunacorpusmesa.pdf (Fecha de consulta: $13 / 02 / 2018)$.

7 Defendemos, con Fuentes (2011: 33), que el estudio de los mecanismos y de las estrategias de (des)cortesía puede extenderse a todo discurso y no reducirse únicamente a los textos orales. Sobre este aspecto, inherente al enfoque de la Lingüística Pragmática, véase González (2014: 127)

8 Padilla (2015: 421) defiende el interés del estudio de estas nuevas formas de discurso que constituyen el presente, al considerar que la "revolución tecnológica y, concretamente, la irrupción de las redes sociales, blogs y plataformas ha supuesto un antes y un después en el modo en que nos comunicamos". 
el estudio de estrategias de descortesia, mediante el recurso a comentarios valorativos de naturaleza subjetiva9 ${ }^{9}$

De otra parte, buscando otros materiales actuales en los que la descortesía no es una excepción sino la norma (cf. Blas, 2001: 11; Fuentes, 2010a: 14; Flores e Infante, 2014: 56; González, 2014: 170, entre otros), hemos consultado los documentos fechados en el siglo XXI en CREA y CORPES XXI relacionados con el tema político, dominio que favorece el discurso persuasivo, el empleo de las emociones como argumento falaz, las actividades de autoimagen y las acusaciones a la imagen del exogrupo (vid. Kienpointner, 2008; Fuentes, 2012, 2013a y 2016; Brenes, 2014; Padilla, 2015; Llamas, 2018).

\subsection{REPRESENTATIVIDAD DE LOS OPERADORES EN EL CORPUS}

Antes de analizar las estrategias argumentativas favorecidas por el significado de por fin, conviene ofrecer algunos datos empíricos que confirman el carácter agresivo y la descortesía del discurso en los medios de comunicación virtual y en el ámbito político.

Para ello, hemos comparado la frecuencia en estos tres corpus (MEsA, CREA y CORPES XXI) de operadores que pueden ofrecer una evaluación subjetiva emotiva (vid. tablas 1 y 2), paradigma que incluye signos de diferente estatuto categorial, como adverbios y locuciones adverbiales emotivas (como afortunadamente, desgraciadamente, por fortuna o por desgracia) y locuciones desiderativas del tipo gracias a Dios, menos mal o por fin ${ }^{10}$.

\begin{tabular}{|c|c|c|c|c|c|c|c|c|c|}
\hline & \multicolumn{9}{|c|}{ Corpus MEsA } \\
\hline & $\begin{array}{c}\text { Tota } \\
1\end{array}$ & $\begin{array}{c}\text { Blog } \\
\text { s }\end{array}$ & $\begin{array}{c}\text { Foro } \\
\mathrm{s}\end{array}$ & $\begin{array}{l}\text { Página } \\
\text { s web }\end{array}$ & $\begin{array}{l}\text { What } \\
\text { s } \\
\text { App }\end{array}$ & $\begin{array}{c}\text { Faceboo } \\
\mathrm{k}\end{array}$ & $\begin{array}{c}\text { Instagra } \\
\mathrm{m}\end{array}$ & $\begin{array}{c}\text { Twitte } \\
\text { r }\end{array}$ & $\begin{array}{c}\text { You } \\
\text { tub } \\
\mathrm{e}\end{array}$ \\
\hline Afortunadamente & 29 & 6 & 4 & 6 & 1 & 6 & 0 & 4 & 2 \\
\hline Felizmente & 4 & 1 & 1 & 1 & 0 & 1 & 0 & 0 & 0 \\
\hline Dichosamente & 0 & 0 & 0 & 0 & 0 & 0 & 0 & 0 & 0 \\
\hline Milagrosamente & 1 & 0 & 0 & 0 & 0 & 1 & 0 & 0 & 0 \\
\hline Lamentablemente & 46 & 8 & 4 & 7 & 1 & 9 & 4 & 8 & 5 \\
\hline Desgraciadamente & 40 & 6 & 4 & 4 & 0 & 9 & 8 & 5 & 4 \\
\hline $\begin{array}{l}\text { Desafortunadamen } \\
\text { te }\end{array}$ & 12 & 1 & 3 & 3 & 2 & 0 & 0 & 3 & 0 \\
\hline
\end{tabular}

\footnotetext{
9 Según Kaul y Cordisco (2014: 145), “el viejo fenómeno de la descortesía verbal se manifiesta activamente remozado en los nuevos medios de comunicación de redes sociales, como Twitter y Facebook". La presencia de la descortesía en estos medios ha sido destacada diferentes investigaciones del ámbito hispánico, como Fuentes (2013b), Díaz (2014) o Padilla (2016 y 2017). 10 Sobre la diferencia entre los adverbios y locuciones emotivas y estas expresiones desiderativas, véase Fuentes (1991). Asimismo, para una delimitación del paradigma de partículas de evaluación emotiva, cf. Meléndez (2009).
} 


\begin{tabular}{|c|c|c|c|c|c|c|c|c|c|} 
Tristemente & 18 & 2 & 2 & 2 & 2 & 4 & 3 & 2 & 1 \\
\hline Infortunadamente & 1 & 0 & 0 & 0 & 0 & 0 & 0 & 0 & 1 \\
\hline Infelizmente & 4 & 2 & 1 & 0 & 1 & 0 & 0 & 0 & 0 \\
\hline Desdichadamente & 0 & 0 & 0 & 0 & 0 & 0 & 0 & 0 & 0 \\
\hline Lastimosamente & 6 & 1 & 0 & 1 & 0 & 0 & 0 & 0 & 4 \\
\hline Por fortuna & 5 & 1 & 3 & 0 & 0 & 0 & 0 & 0 & 1 \\
\hline Por suerte & 55 & 11 & 9 & 12 & 3 & 7 & 1 & 6 & 6 \\
\hline Por desgracia & 81 & 12 & 14 & 7 & 6 & 8 & 10 & 14 & 10 \\
\hline Gracias a Dios & 33 & 10 & 2 & 1 & 4 & 5 & 5 & 5 & 1 \\
\hline Menos mal & 117 & 12 & 6 & 11 & 27 & 14 & 13 & 25 & 9 \\
\hline Por fin & 124 & 30 & 6 & 15 & 12 & 12 & 24 & 10 & 15 \\
\hline
\end{tabular}

Tabla 1: Frecuencia de los operadores en MEsA

\begin{tabular}{|c|c|c|c|c|}
\hline & \multicolumn{2}{|c|}{ CREA (s. XXI) } & \multicolumn{2}{|c|}{ CORPES XXI } \\
\hline & Total & $\begin{array}{l}\text { Politica, } \\
\text { economia, } \\
\text { comercio y } \\
\text { finanzas }\end{array}$ & Total & $\begin{array}{l}\text { Política, } \\
\text { economia y } \\
\text { justicia }\end{array}$ \\
\hline Afortunadamente & 467 & 63 & 3608 & 424 \\
\hline Felizmente & 155 & 19 & 1142 & 100 \\
\hline Dichosamente & 2 & 2 & 34 & 3 \\
\hline Milagrosamente & 73 & 6 & 605 & 46 \\
\hline Lamentablemente & 357 & 52 & 3750 & 832 \\
\hline Desgraciadamente & 291 & 46 & 1977 & 348 \\
\hline Desafortunadamente & 88 & 16 & 1224 & 254 \\
\hline Tristemente & 97 & 23 & 798 & 157 \\
\hline Infortunadamente & 5 & 2 & 167 & 49 \\
\hline Infelizmente & 1 & 0 & 59 & 10 \\
\hline Desdichadamente & 9 & 0 & 61 & 7 \\
\hline Lastimosamente & 8 & 1 & 358 & 66 \\
\hline Por fortuna & 176 & 17 & 1668 & 109 \\
\hline Por suerte & 256 & 9 & 3161 & 137 \\
\hline Por desgracia & 248 & 17 & 1823 & 218 \\
\hline Gracias a Dios & 160 & 18 & 792 & 63 \\
\hline Menos mal & 158 & 12 & 2161 & 107 \\
\hline Por fin & 1544 & 84 & 14940 & 657 \\
\hline
\end{tabular}

Tabla 2: Frecuencia de los operadores en CREA y CORPES XXI 
De una parte, el análisis de la frecuencia de los adverbios en el corpus MEsA presenta lamentablemente y desgraciadamente como los operadores más repetidos (46 y 40 casos), por delante de afortunadamente (29 registros). Estos resultados contrastan con los recogidos en el siglo XXI en los corpus académicos: así, en CREA las documentaciones de afortunadamente superan las de lamentablemente y desgraciadamente (467 frente a 357 y 291, respectivamente); por otra parte, mientras que en MEsA felizmente (4 casos) se sitúa por detrás de adverbios de evaluación negativa como desafortunadamente (12), tristemente (18) o lastimosamente (6), en CREA su frecuencia supera claramente a tales signos (155 casos para felizmente, frente a 88, 97 y 8 , respectivamente, para los tres adverbios de evaluación negativa citados). A esta linea apuntan los resultados del CORPES XXI que presentan a afortunadamente (3608 casos) con una frecuencia muy superior a desgraciadamente (1977) o a felizmente (1142 casos), preferido este a tristemente (798).

Sin embargo, al limitar temáticamente los ejemplos de los corpus académicos al dominio que incluye la política (politica, economia, comercio y finanzas en CREA; politica, economía y justicia en CORPES XXI), los resultados se asimilan más con los del corpus MEsA, con una preferencia por los adverbios negativos. Por ejemplo, en CORPES XXI lamentablemente es el adverbio más repetido en discursos relacionados con el ámbito citado, duplicando prácticamente a afortunadamente ( 832 frente a 424 casos). Por otra parte, al igual que en MEsA, las valoraciones negativas mediante desafortunadamente o tristemente son más frecuentes que las positivas con felizmente en CORPES XXI (254 y 157 registros frente a 100); a su vez, CREA registra más casos de tristemente frente a felizmente (23 a 19 registros) en textos del ámbito de la política, economía, comercio y finanzas.

Asimismo, la comparación de las locuciones adverbiales emotivas confirma esta tendencia: frente a los datos globales de los corpus académicos en los que por suerte (256 casos en CREA y 3161 en CORPES XXI) es preferida a por desgracia (248 registros en CREA y a 1823 en CORPES XXI), los textos restringidos temáticamente al área que incluye la politica sitúan a por desgracia como el signo preferido por los hispanohablantes, duplicando los registros de por suerte (17 frente a 9 casos en CREA y 218 frente a 137 en CORPES XXI). Por su parte, el discurso en Internet recogido en MEsA (tabla 1), caracterizado por la agresividad verbal y el anonimato de los usuarios, muestra también una preferencia por las evaluaciones negativas con por desgracia (81 casos), frente a las locuciones de sentido positivo por suerte y por fortuna (55 y 5 registros, respectivamente).

Finalmente, una revisión de las locuciones desiderativas gracias a Dios, menos mal y por fin en el corpus MEsA confirma que estos medios digitales recurren menos a la invocación religiosa con gracias a Dios (33 casos) y privilegian el uso de expresiones reactivas como menos mal (117 ejemplos) y por fin (124 registros). Si bien estas últimas expresiones desiderativas tienen una orientación favorable, no ha de extrañar su preferencia sobre adverbios 
como afortunadamente o locuciones emotivas como por suerte o por fortuna, puesto que, de una parte, menos mal y por fin tienen una gran "carga modal y expresiva" (Fuentes, 1991: 318) y, sobre todo, un valor de alivio que no conllevan los adverbios y locuciones citados; por otra parte, tanto menos mal como por fin pueden servir a estrategias argumentativas que encierran descortesía encubierta (nos referimos a casos en los que menos mal, con valor irónico, se acerca en su significado a oraciones como faltaría más o a ejemplos de por fin en los que puede asociarse a expresiones del tipo ya tocaba, que, como veremos más adelante, tienen una connotación negativa, al evocar la larga espera ante un hecho deseado mucho tiempo) ${ }^{11}$.

En definitiva, todos estos datos confirman que los corpus escogidos en esta investigación (las fuentes digitales de MEsA y los limitados a la esfera política en CREA y CORPES XXI) son representativos del lenguaje empleado en estos discursos, donde la agresividad de los hablantes y la búsqueda de la confrontación favorecen el recurso a las emociones y la subjetividad mediante operadores modales de evaluación desfavorable o locuciones desiderativas que pueden conllevar descortesía, en ocasiones encubierta.

\section{MARCo TEÓRICO-METOdOLÓGICO}

En este trabajo nos interesamos por el análisis de por fin como operador modal (Fuentes, 2009a: 270) y, en particular, por la manera en que su significado puede ser utilizado con fines argumentativos en el discurso digital y político, facilitando operaciones de imagen (facework), estrategias de cortesía o actuando como atenuador o intensificador de la descortesía verbal ${ }^{12}$.

Desde una perspectiva que considera el estudio de la cortesía y la descortesía como un continuum (Kienpointner, 2008) y partiendo de la hipótesis defendida por Fuentes (2012: 49), que considera el recurso a la subjetividad y a las emociones como un medio "altamente rentable" en la búsqueda de la cortesía y la descortesía ${ }^{13}$, nuestro trabajo busca adentrarse en el análisis de este operador asociado a la expresión de la modalidad y al plano emotivo.

Para aclarar la interconexión entre modalidad y argumentación nos servimos de la siguiente citación de Fuentes (2012: 54): "Desde un punto de

\footnotetext{
${ }^{11}$ Los datos de CREA y CORPES XXI muestran a por fin como el signo más repetido, si bien conviene recordar la gran cantidad de casos en los textos escritos los que no actúa como operador modal (valor aquí tratado), sino como mero conector temporal que cierra una enumeración o narración de acciones. Sobre la diferencia entre ambos usos, remitimos a Fuentes (2009a: 270-271).

12 Briz (2009: 69) recuerda que el recurso a la modalización puede suponer "una intensificación o atenuación de lo que se dice y del punto de vista del hablante".

${ }^{13} \mathrm{El}$ estudio del empleo de la emoción con fines estratégicos o argumentativos en la interacción ha sido abordado en los estudios de (des)cortesía en español. Además de los trabajos de Fuentes (2012, 2013a y 2014) destacamos a Kienpointner (2008: 27) que defiende la relación dialéctica entre las emociones y la (des)cortesía y considera la integración de las primeras como un "avance en la teoría de la (des)cortesía". Véase, asimismo, Padilla (2015: 430) sobre el empleo de la emoción como atenuador de la descortesía en el discurso político.
} 
vista pragmalingüístico y desde una teoría de la enunciación, (Bally, Benveniste), el tema de la modalidad es tratado como una dimensión pragmática que se manifiesta a través de operadores específicos: los modalizadores. Estos actúan dentro del enunciado y, aparte de mostrar la actitud subjetiva del hablante, pueden ser empleados con un fin argumentativo". Según este enfoque, el recurso a estos operadores modales actúa estratégicamente como arma argumentativa que puede contribuir a la construcción o deterioro de una imagen e identidad, favorecer estrategias de afiliación y funcionar como mecanismo de atenuación o intensificación de la (des)cortesía ${ }^{14}$.

Nuestro objetivo último es describir cómo el significado de un operador lingüístico de modalidad como la locución por fin, explicable por medio de operaciones discursivas y estrategias enunciativas, puede ponerse al servicio de los fines argumentativos, favoreciendo trabajos de imagen e identidad y estrategias de (des)cortesía en discursos persuasivos de naturaleza variada ${ }^{15}$. Asimismo, pretendemos demostrar que, como todo mecanismo lingüístico, este operador no es inherentemente cortés o descortés (cf. Landone, 2009), sino que puede emplearse con diferentes intenciones argumentativas y favorecer estrategias diversas según la relación entre los hablantes, el tipo de discurso o el tema tratado ${ }^{16}$.

Con una perspectiva próxima a la Lingüistica Pragmática (Fuentes, 2017 [2000]), basada en las relaciones mutuas entre la pragmática y la gramática y la pragmática y semántica, nuestro estudio de por fin busca destacar la influencia directa entre el significado de este operador de modalidad $\mathrm{y}$ las funciones argumentativas que pone en juego en el nivel discursivo ${ }^{17}$.

En este sentido, parece adecuado un enfoque como el defendido en Fuentes (2012: 49), que defiende una pragmalingüistica de carácter integral donde se encuentran íntimamente relacionadas "la teoría de la enunciación, la teoría de la argumentación y la cortesía verbal".

\footnotetext{
14 Según este punto de vista, la subjetividad puede funcionar como "elemento codificado lingüísticamente (la modalidad), que actúa como un calificador de la argumentación [...] e intensifica, atenúa o invierte el valor cortés o descortés de un elemento" (Fuentes, 2012: 54).

${ }^{15}$ La relación entre operadores y partículas modales y el marco de la (des)cortesía ha sido desarrollada en numerosos trabajos del español, como Martín (2001) o Landone (2009), y, más recientemente, Manceda (2014) o Padilla (2016 y 2017), orientados a los nuevos medios de comunicación virtual.

${ }^{16} \mathrm{Al}$ estudiar partículas que favorecen la interactividad en Twitter, Padilla (2016: 198) muestra "cómo, dependiendo de la intencionalidad del locutor, pueden servir para vehicular actos corteses o descorteses". Esta caracterización retoma la tesis de Haverkate (1987: 33), para quien "son las circunstancias en las que se emplean las oraciones las que determinan la calificación de cortesía (ninguna oración es inherentemente cortés o descortés)".

${ }^{17}$ La relación entre el significado base y el funcionamiento discursivo de estos signos ha sido tratado en estudios recientes como los de Martín (2010) o Murillo (2010). Véanse también las aportaciones de Portolés (2004: 304-305) que defiende la validez de la pragmática lingüística como perspectiva de estudio lingüístico, afirmando que las lenguas "no sólo se diferencian en su gramática, sino también en sus significados y en los usos que desencadenan estos significados".
} 
Además del vínculo, ya comentado, entre modalidad y argumentación, esta perspectiva destaca la necesaria interrelación entre el marco de la cortesía y la teoría de la argumentación en la lengua, la cual "arroja nueva luz dentro de la pragmática lingüística” (Fuentes, 2012: 51) ${ }^{18}$.

El enfoque de la teoría de la argumentación en la lengua (Anscombre y Ducrot, 1983) ha sido defendido por numerosos autores (vid. Portolés 2004: 233, Murillo, 2010: 244 y 259-263; Martín 2010: 108-112, entre otros), al ofrecer un marco que permite observar las instrucciones que diferencian a signos de significado próximo, atendiendo a las operaciones discursivas que configuran su información semántica en el nivel de la lengua, que deben tenerse en cuenta para la explicación de sus usos.

Con origen en esta teoría de la argumentación, parece oportuno recurrir, asimismo, a la teoría polifónica de la enunciación, de gran difusión en la lingüistica francesa (vid. Anscombre et al., 2013 y 2018; Donaire, 2006, 2012 o 2013a), enfoque que defiende el carácter dialógico de la lengua, entendiendo como inherentes a la lengua las dinámicas polifónicas que activan estos operadores.

De acuerdo a este enfoque, pasamos a explicar el significado de por fin, describiendo las operaciones que instruye en relación con distintas formas de discurso convocadas o evocadas, las cuales pueden ser explotadas argumentativamente para favorecer operaciones de construcción de imagen e identidad, así como para facilitar estrategias de afiliación y de (des)cortesía en español.

\section{ANÁLISIS DE POR FIN}

Como indica la definición del diccionario de Briz et al. (2008), por fin "presenta el miembro del discurso en el que aparece como un acontecimiento deseable que pone término a un proceso esperado". Este rasgo de la larga espera se repite en las definiciones de esta locución en diccionarios especializados; así, Fuentes (2009a: 270-271) describe por fin como operador modal que, presupone un "hecho esperado" y cuyo "valor temporal originario no se pierde", al servir "como indicador del final de una espera". A su vez, Santos (2003: 394) indica que por fin indica "a veces la idea añadida de espera y preocupación"19.

\footnotetext{
${ }_{18}$ Así lo indica Fuentes (2012: 55): "Cortesía y argumentación aparecen entrelazados en el tratamiento de los operadores de modalidad". Sobre la relación entre la argumentación y la cortesía, remitimos también a Fuentes (2009b y 2013a) y Alcaide (2014).

${ }_{19}$ Asimismo, los diccionarios generales del español recogen la idea de espera y subrayan las dificultades previas encontradas que caracterizan el significado de por fin. Así, DRAE (s.v. fin) apunta que sirve para "expresar con cierto énfasis el término de una situación de espera", DEA (s.v. fin) explica que "que la acción se ha realizado después de esperar mucho o de superar muchos obstáculos", DUE (s.v. fin) indica "después de haber esperado mucho o haber pasado por diversas vicisitudes" y LEMA (s.v. fin) alude a la paráfrasis "por último, después de vencer todos los obstáculos".
} 
Estas definiciones confirman el valor polifónico del significado de por fin, que, al igual que otros operadores de evaluación emotiva como afortunadamente, por suerte o por fortuna, ofrece una orientación favorable del discurso que evalúa, pero que se diferencia de estos por su valor temporal, que presenta a dicho discurso deseado como posterior y poniendo fin a otro discurso anterior ${ }^{20}$.

Para entender esta descripción partiremos de la descripción clásica de Cadiot et al. (1985: 199) del signo enfin del francés:

En énonçant enfin, le locuteur signifie qu'une entité linguistique $\mathrm{X}$ accompagnée par enfin fait qu'il n'y a plus lieu de donner à un discours $Z$ antérieur à $\mathrm{X}$ une suite $\mathrm{Y}$ envisageable avant l'énonciation de X. X apparaît alors comme mettant fin au discours amorcé en $Z$. En d'autres termes, le locuteur, en accompagnant X par enfin, donne à son énonciation de $\mathrm{X}$ la fonction de mettre fin à un discours $Z$ précédent, fonction qui s'ajoute à l'acte illocutoire propre à $\mathrm{X}^{21}$.

Adoptando esta delimitación al operador modal por fin del español, podemos afirmar que esta locución instruye, desde un punto de vista enunciativo, una orientación favorable con respecto al discurso $\mathrm{X}$ evaluado (generalmente explícito y presentado tras por fin), el cual ha sido esperado largo tiempo y pone fin o término a una situación necesariamente anterior recogida en un discurso implícito o explícito (al que podría identificarse con $Z$, siguiendo a Cadiot et al., 1985) 22 .

Veamos ahora cómo este significado polifónico, que distingue a por fin de otros operadores evaluativos como afortunadamente o por suerte, favorece determinadas funciones argumentativas en español y, en particular, en los medios digitales y el dominio político analizados.

\footnotetext{
${ }^{20}$ Este valor temporal tampoco es inherente a otros operadores desiderativos como gracias a Dios o menos mal.

${ }^{21}$ Cadiot et al. (1985: 212-213) analizan detalladamente las distintas condiciones de empleo de los diferentes usos de enfin, destacando que los empleos con valor de alivio (cercanos al del operador modal por fin aquí estudiado) marcan un cambio, ruptura o discontinuidad con respecto a una situación anterior no satisfactoria (presentada en un discurso previo), cambio que es percibido como feliz por el locutor y que presupone que se esperaba que la situación negativa anterior terminara; este empleo de enfin conlleva una reacción afectiva positiva, que puede ser acompañado de entonación exclamativa. Sin ánimo de profundizar en la descripción del operador enfin, que excedería los limites del presente trabajo, remitimos a Cadiot et al. (1985: 215217) sobre las semejanzas y diferencias entre este empleo evaluativo de enfin y los valores de enfin como operador que marca el final de un proceso.

Asimismo, una excelente descripción del valor polifónico del operador enfin se encuentra en los trabajos de Donaire (2013a y 2013b), que diferencian diferentes estrategias discursivas puestas en juego por este signo y, al tratar las propiedades semántico-pragmáticas afines a este valor de alivio (Enfin 1, en los trabajos citados), hacen referencia al vínculo temporal entre dos segmentos discursivos: $\mathrm{X}$ (situado en el contexto inmediato a enfin) e $\mathrm{Y}$, siendo el primero posterior (enunciativa y/o cronológicamente) a Y.

${ }^{22} \mathrm{El}$ esquema enunciativo sería el siguiente: 'Decir por fin, (X) es decir X (deseado y de orientación favorable) pone fin a $Z$ (anterior). Adviértase, asimismo, que la presencia de $\mathrm{X}$ evita una continuación discursiva $(\mathrm{Y})$ que hubiera podido tener lugar si no se hubiera puesto fin a $Z$.
} 
En primer lugar, a diferencia de afortunadamente o por suerte, esta locución no conlleva el matiz de fortuna que ayuda a preservar una imagen ${ }^{23}$ de modestia, sino que subraya más bien la satisfacción, alegría, desahogo o alivio personal al presentar un resultado obtenido tras una larga espera, como ilustran los ejemplos (1) y (2), tomados de un blog y de WhatsApp:

(1) La entrada de hoy es muy especial porque por fin sale a la luz un gran proyecto en el que he estado trabajando desde hace unos cuantos meses junto con mi amiga y diseñadora, María Pascual. (MEsA: BL 2016 jun COL 05, pp. 12)

(2) 29/5/17, 15:04 - M1: Cómo estáis chicas ${ }^{24}$

29/5/17, 15:05 - M1: Yo negra, pero por fin he acabado mi trabajo fin de Máster (MEsA: WA 2016-17 oct-jul, pp. 827)

En ambos casos, por fin introduce una orientación favorable hacia un discurso $\mathrm{X}$ que le sigue (sale a la luz un gran proyecto y he acabado mi trabajo de fin de Máster, respectivamente), muy deseado. El ejemplo (1) permite ilustrar que ese discurso evaluado favorablemente con por fin pone término a una larga espera previa, explícita (en el que he estado trabajando desde hace unos cuantos meses); a su vez, el adjetivo negra que precede la aparición de por fin en (2) deja entrever un discurso implícito $(Z)$ relativo al esfuerzo y espera previa prolongada anterior al término del trabajo.

Desde un punto de vista argumentativo, a diferencia de la estrategia de autoimagen de modestia inherente al valor fortuito de afortunadamente o por suerte, al utilizar por fin se concede a la propia enunciación un valor de desahogo o alivio. A través de este operador modal, la subjetividad se hace "forma lingüística (modalidad): caracteriza al enunciado y lo inscribe en relación con el hablante" (Fuentes, 2012: 64). La función argumentativa de por fin puede ayudar en estos empleos a reforzar una imagen de autocrítica hacia el propio trabajo, reconociendo la responsabilidad ante la larga espera y la tardanza con la que tiene lugar el acontecimiento presentado. Sirva de muestra el siguiente ejemplo, tomado de un blog político en CORPES XXI:

(3) ¡Por fin me he animado! Aunque me ha costado... Hacer un blog es un gran compromiso, si quieres que alguien te lea. Y en la blogosfera hay tantos blogs... (CORPES: Villanueva, J., "Mi primer post", 2010)

\footnotetext{
${ }^{23} \mathrm{El}$ término imagen (del inglés face) tiene su origen en Goffman (1967) y ha sido desarrollado especialmente a partir de la obra de Brown y Levinson (1987). Como indica Brenes (2014: 65), la imagen corresponde "a la representación que el hablante crea de sí mismo durante la interacción, esto es, a la forma en la que el emisor intenta ser percibido por el resto de interlocutores durante el intercambio comunicativo".

${ }^{24}$ Siguiendo las indicaciones de los redactores de la guía del corpus MEsA, reproducimos fielmente los ejemplos, sin modificar signos de puntuación o errores ortográficos, dado que no limitan la comprensión de los mensajes.
} 
En este texto, el autor del blog "hace material lingüístico lo que pertenece al plano emotivo y lo usa en provecho para conseguir sus fines comunicativos" (Fuentes, 2012: 80); así, en aras de evitar posibles críticas de sus lectores por la larga espera, se sirve del operador modal por fin para reconocer su grado de culpabilidad en el retraso de la publicación (aunque destacando, eso sí, las dificultades pasadas en el largo proceso).

Por otra parte, como indica Fuentes (2012: 49), la expresión de la subjetividad puede utilizarse en la argumentación como un "medio de asegurar la afiliación con el interlocutor". Aunque no es una estrategia muy frecuente en el corpus analizado, la función del operador de modalidad por fin puede interpretarse argumentativamente como estrategia de cortesía positiva valorizante (cf. Fuentes, 2010a: 65) que maximiza o refuerza el aprecio, el afecto y la empatía con la dicha del interlocutor (4) o de una tercera persona (5):

(4) De tanto buscar has encontrado por fin a tu padre lindos recuerdos. (MEsA: IG 2017 jun-ago MIC 01, pp. 625)

(5) Este actor era puro carisma en pantalla, ahora está de capa caida pero todas sus peliculas han plagado mi infancia y adolescencia y las he visto docenas de veces cada una. Por fin alguien le da el reconocimiento que se merece. (MEsA: BL 2010 may ESP 01, pp. 419)

En ambos ejemplos, con por fin el hablante manifiesta compartir su alegría ante el evento tanto tiempo deseado que introduce el discurso X evaluado: has encontrado a tu padre en (4) y alguien le da el reconocimiento que se merece en (5). Estamos ante un uso argumentativo de por fin que confirma el recurso a un operador de modalidad con una función empática como estrategia de afiliación con los deseos del interlocutor (4) o del actor (5) ${ }^{25}$.

Véase, asimismo, el uso de por fin en (6), donde la reduplicación y la entonación exclamativa habituales en el lenguaje digital confirman su carga modal de alegría y su valor expresivo al introducir un discurso X deseado (podemos ver en las salas de cine españolas 'Colossal'):

(6) ¡Por fin! Por fin podemos ver en las salas de cine españolas 'Colossal', la nueva y esperadísima película de Nacho Vigalondo de la que venimos escuchando todo tipo de alabanzas y piropos desde hace casi más de un año. (MEsA: BL 2017 jun-jul ESP 06, pp. 465)

El estudio del corpus MEsA confirma que una de las funciones argumentativos más habituales de por fin es su uso como estrategia de descortesía

\footnotetext{
${ }^{25}$ Estos casos de empatía y de afiliación con los deseos del interlocutor son característicos de la cultura de acercamiento hispanohablante que promueve la cortesía valorizante, como han señalado, entre otros, Kienpointner (2008: 34), González (2014: 119) o Kaul (2017: 6).
} 
encubierta (off record según Brown y Levinson, 1987: 215), con las que se enmascara u oculta la verdadera intención del hablante. Estas estrategias son habituales en intervenciones reactivas en Internet, ya sea en redes como Instagram (ejemplo 7), blogs (8) o foros digitales (9):

(7) Por finnn ${ }^{26}$ se echaba de menos!!! (MEsA: IG 2017 sep-nov RIS 03, pp. 1283)

(8) Hola!! por fin una nueva entrada!!! jajaja te echabamos de menos!!! (MEsA: BL 2016 ago SAR 01, pp. 143)

(9) Hombre por fin post oficial de esta serie, ya tocaba $\mathrm{xD}$. (MEsA: FO 2014-16 VAN 01, pp. 305)

En los tres ejemplos, los usuarios anónimos se sirven de un operador modal, en apariencia, favorable como por fin con un fin argumentativo negativo subyacente ${ }^{27}$; el matiz de larga espera inherente al significado de por fin introduce una crítica velada hacia el interlocutor, al que se le acusa indirectamente de haber tardado mucho tiempo en presentar su entrada o post, como confirman las continuaciones discursivas se echaba de menos en (7), te echabamos de menos en (8) o ya tocaba en (9). Estamos ante una reprobación encubierta que reside en la inferencia, mediante un operador de modalidad empleado argumentativamente con sentido irónico para suavizar la descortesía de una crítica que amenaza la imagen del interlocutor.

Los usuarios intentan minimizar el impacto de su reproche para no ser descorteses; para ello, acompañan el empleo de por fin con estrategias desfocalizadoras como el impersonal se (se echaba de menos) en (7) o el plural (te echabamos de menos) en (8). Por otra parte, en estos medios virtuales es habitual recurrir al tono humorístico y a la risa como atenuadores de la descortesia, que rebajan la agresividad del ataque; así lo ilustra la expresión jajaja en (8) o el emoticono $x D$ de risa que cierra el ejemplo (9) y que actúa como pista ostensiva para facilitar la inferencia (Padilla, 2017: 463).

Otra función argumentativa habitual de por fin en estos medios virtuales es su empleo en intervenciones reactivas como estrategia de afiliación grupal y de refuerzo de la imagen del interlocutor, con el que se identifica el hablante y al que se asocia con atributos valorados socialmente, como la sinceridad, el sentido común, la normalidad o la moderación y sensatez. Sirvan

\footnotetext{
${ }^{26}$ Además del alargamiento de la consonante final (finnn) para suplir los rasgos suprasegmentales, en esta intervención reactiva cabe destacar que el discurso X evaluado por fin no aparece explícito. La consulta del corpus MEsA permite apreciar que estamos ante una reacción expresiva de un usuario anónimo ante el anuncio inminente de un programa televisivo (X sería entonces un discurso implícito del tipo el programa llega a las pantallas).

${ }^{27} \mathrm{El}$ empleo de lo positivo con fines negativos es un medio de argumentación habitual en la actividad política, como indica Fuentes (2012: 71). Cf. Kienpointner (2008: 29), Fuentes (2013a: 12) o Manceda (2014: 170) sobre la ironía como forma indirecta de la descortesía.
} 
de muestra los ejemplos siguientes de MEsA, tomados de páginas web (10) y de redes sociales como Facebook (11), Instagram (12) o Twitter (13):

(10) Pues este señor tiene más razón que un santo. ¡iAlabado sea el señor!!!, por fin alguien que llama las cosas por su nombre. (MEsA: PW 2016 sep-oct PAI 02, pp. 121)

(11) Hombree, por fin alguien con sentido común por aqui ;-) (MEsA: FB 2016 jun CHI 02, pp. 35)

(12) Por fin una persona normal. (MEsA: IG 2017 ago VEG 01, pp. 458)

(13) Ya era hora. Por fin un poco de moderación y sensatez. (MEsA: TW 2017 jul-sep TOD 10, pp. 753)

El recurso al operador modal de orientación favorable por fin, que marca la satisfacción o desahogo del hablante ante el esperado término a una búsqueda alargada, contribuye a la afiliación del hablante con su interlocutor y su grupo al que confiere unos valores socialmente positivos, en una actividad que refuerza asi su propia autoimagen. Este comportamiento comunicativo favorece, por lo tanto, una estrategia de afiliación grupal del hablante, que se identifica con características positivas (sensatez, sentido común, moderación, etc.) que definen a un grupo de individuos (entre los que figura su interlocutor), los cuales comparten estos valores con los que el hablante desea verse y ser visto por los demás en estos medios digitales.

Asimismo, con una intención de refuerzo de su autoimagen, el hablante puede recurrir a por fin para afiliarse con la ideologia de lo políticamente correcto (cf. Fuentes, 2010b), ante temas sensibles como el apoyo en favor de los discapacitados que muestra el texto (14) del CREA:

(14) Si a esto unimos que la Universidad de Salamanca prepara ya el VII Máster de Integración de Personas con Discapacidad, podremos comprobar la trascendencia que han adquirido el movimiento asociativo y las personas con minusvalía. Además, tiene una segunda lectura, la discapacidad es ya un yacimiento de empleo, por fin, reconocido. (CREA: Accesible. Revista de información sobre discapacidad, 14, 04/2001)

Nuevamente, el empleo del operador modal por fin responde a una función argumentativa que permite al hablante expresar su alegría y posicionarse favorablemente ante la consecución de un logro largamente deseado (el reconocimiento de la discapacidad como yacimiento de empleo). Al mismo tiempo, las emociones se gestionan argumentativamente por el hablante para adherir e identificarse con esa imagen politicamente correcta que la sociedad proyecta de sí misma en el discurso público y que defiende una visión sensible y empática ante grupos protegidos, como los minusválidos. 
Por otra parte, en discursos de naturaleza politica es muy habitual el uso de un operador de modalidad como por fin cuando se recurre a la emoción como argumento falaz para minusvalorar la imagen de personajes públicos. La elección de por fin permite emplear la evaluación positiva con un fin argumentativo negativo (cf. Fuentes, 2012: 71), como ilustra el texto (15), del CORPES XXI, donde el autor del blog se sirve de por fin para atacar a Aznar y reforzar, así, su identidad (cf. Fuentes, 2013b28) y su vínculo ideológico con sus lectores:

(15) Como ha dicho esta semana un -por fin...- prudente Aznar togado de rojo, urge crear "una gran corriente de confianza". (CORPES: Rufino, T., "Mi primera crisis", 2009-01-24)

Lo que, en principio, parecería aquí un elogio al antiguo presidente del Gobierno, encierra realmente un ataque a su imagen pública al dejar entender que la prudencia es una virtud que no le ha distinguido hasta la fecha y que llega muy tarde, tras una espera mayor a la deseada. En este sentido, los puntos suspensivos dejan abierta la interpretación de esta reprobación o crítica a Aznar ante la ciudadanía. La descortesía encubierta que encierra el uso argumentativo de por fin en el terreno político a través de blogs contribuye así a un trabajo de identidad y a un deseo de afiliación grupal con los rasgos ideológicos compartidos y esperados por la audiencia.

Para concluir nuestro análisis, cabe destacar que, en muchos otros casos, el recurso a por fin no encierra ninguna interpretación ambigua, al actuar directamente como intensificador de la descortesía en actos verbales deliberados de fustigación (cf. Kaul, 2017) a la imagen de personajes públicos, a los que se denigra. Tales actos agresivos son habituales en el discurso en Internet, donde la identidad virtual y el anonimato que caracterizan las intervenciones de los usuarios en estos medios digitales favorecen los ataques hostiles sin riesgo para la propia persona. Sirva de muestra el comentario de un usuario anónimo en YouTube de (16), que se sirve de por fin para manifestar abiertamente su alegría por la expulsión, largo tiempo deseada, de una concursante de un programa televisivo a la que ataca e insulta:

(16) Pues por fin la impresentable de XILENE fuera!!! Ahora solo falta que la echen de España (MEsA: YT 2017 jun MAS 01, pp. 705)

La descortesía que reina en estas intervenciones de internautas en los medios de comunicación virtual puede entenderse como un trabajo de construcción identitaria y una estrategia de afiliación grupal con otros usuarios que comparten ese lenguaje conscientemente ofensivo, que incluye insultos para descalificar al personaje público denigrado (cf. Díaz, 2014: 81-82).

\footnotetext{
${ }^{28}$ Siguiendo a esta autora, el concepto identidad se utiliza en referencia al carácter grupal de la imagen.
} 


\section{Conclusiones}

En esta investigación, hemos pretendido mostrar el interés de un enfoque pragmalingüístico integral para el estudio de los operadores modales que combine las aportaciones de la teoría de la argumentación, de la enunciación y de la (des)cortesía verbal, destacando la importancia de relacionar los valores semántico-discursivos inherentes al significado de estos signos con el estudio de las estrategias que ponen en juego en sus empleos discursivos.

Con un enfoque multidimensional centrado en el estudio de estos operadores evaluativos en discursos del español actual caracterizados por la agresividad verbal y la presencia de la descortesía, hemos comparado materiales variados del dominio panhispánico recogidos en el corpus digital MEsA (procedentes de páginas web, foros, redes sociales, etc.) con documentos relativos al ámbito político de los corpus académicos CREA y CORPES XXI, lo que nos ha permitido comprobar una preferencia de los hispanohablantes por el empleo de operadores de evaluación emotiva negativa o por expresiones desiderativas como menos mal o por fin, de gran difusión en contextos reactivos y empleadas como estrategias de descortesia encubierta.

Asimismo, centrando nuestra atención en el operador por fin, hemos buscado mostrar que el significado polifónico de base de este signo instruye una orientación favorable con respecto al segmento discursivo evaluado, el cual pone término a una larga espera previa, generalmente implícita, aunque fácilmente deducible.

Este rasgo inherente al significado de por fin se mantiene en español en sus diferentes usos. Así, la comparación del empleo de este signo en muestras reales como las recogidas en los corpus MEsA, CREA y CORPES XXI permite confirmar que este mismo operador no puede ser considerado inherentemente como marcador de cortesía o de descortesía.

Nuestra investigación confirma que por fin puede servir, en primer lugar, en operaciones de autoimagen como mecanismo de autocritica para anticipar posibles reproches ante un resultado que ha tardado en llegar.

En segundo lugar, aunque menos frecuente en el corpus analizado, la expresión de alegría inherente a este operador de modalidad puede emplearse argumentativamente como refuerzo de cortesía positiva para manifestar empatía y afiliación con los deseos del interlocutor o de una tercera persona apreciada, ante un evento deseado mucho tiempo.

Otro caso muy habitual en los medios de comunicación virtual es el uso de por fin como estrategia de descortesia encubierta, donde se recurre a este operador modal, de orientación argumentativa aparentemente favorable, para hacer una crítica indirecta (por su valor añadido de larga espera), con 
un sentido irónico que atenúa el reproche y que va acompañado en ocasiones de cierto humor o emoticonos que suavizan el ataque a la imagen del interlocutor.

Asimismo, en estos medios digitales por fin puede ser empleado argumentativamente como estrategia de afiliación grupal o de identidad de los hablantes que se identifican con otros usuarios a los que se atribuyen valores sociales positivos, con los que desean ser vistos en el discurso público.

Por otra parte, la búsqueda constante en el discurso de naturaleza politica del refuerzo de la autoimagen explica el uso de por fin para adherir y afiliarse a la ideología de lo politicamente correcto, a favor de temas sensibles para la ciudadanía, haciendo uso de las emociones y de la subjetividad como estrategias persuasivas en provecho de los fines comunicativos.

En el ámbito político, de carácter agonal, destaca igualmente el recurso a por fin como argumento falaz para descalificar o minusvalorar a personajes públicos de tendencias politicas contrarias, en una estrategia de descortesía encubierta consistente en partir de un operador modal de evaluación aparentemente positiva para atacar la imagen ajena. La función argumentativa de por fin puede contribuir, así, al trabajo de identidad del autor de blogs de naturaleza politica que, al recurrir a esta estrategia de descortesía encubierta hacia personajes públicos, se afilia con una ideologia con la que sus lectores (como entidad grupal) pueden sentirse atraídos e identificados.

Finalmente, el anonimato que oculta la identidad de los usuarios en el discurso digital, donde la agresividad verbal es cada vez más palpable, explica el uso de por fin como intensificador de la descortesía de fustigación, al servir como expresión de alegría ante la desdicha ajena, en comentarios salpicados de descalificaciones e insultos que permiten a los internautas afiliarse con grupos de usuarios que comparten ese lenguaje provocador.

En definitiva, la comparación de materiales reales en diversas fuentes ha permitido observar cómo el recurso al operador por fin, como expresión modal de la actitud subjetiva de alegria, satisfacción, desahogo o alivio del hablante y que conserva ese significado base de poner término a una larga espera, puede responder a fines estratégicos diversos en el nivel discursivo $^{29}$, funcionando como arma argumentativa de gran eficacia persuasiva.

Entre las pistas que podrian ampliar en el futuro los objetivos del presente trabajo se situaría la comparación de este u otros operadores evaluativos con signos afines de otras lenguas ${ }^{30}$, lo que permitiría acercarse a un

\footnotetext{
${ }^{29}$ Como indica Fuentes (2012: 63), no siempre existe una correspondencia entre la emoción positiva (o, en nuestro caso, el operador de evaluación favorable) y entre la emoción negativa y la descortesía.

30 Sin ánimo de exceder los límites de este trabajo, podemos apuntar que un estudio comparativo entre por fin y enfin del francés, permite observar que el valor de operador modal de por fin como indicador de alivio o satisfacción que pone fin a una espera comparte con el enfin 1, descrito en Donaire (2013a: 141 y 2013b: 109), la posibilidad de ser repetido (como en el ejemplo 6) y de aparecer con exclamaciones (casos de 3, 6, 7, 8 o 16) o en incisos (como ilustra el texto 15).
} 
aspecto probablemente menos tratado en los estudios de imagen y (des)cortesía, al abordar análisis contrastivos, con base en las instrucciones semántico-discursivas de estos operadores modales para dar cuenta de las afinidades y diferencias en las estrategias argumentativas que ponen en juego tales signos en las lenguas acotadas.

\section{REFERENCIAS}

ALCAIDE LARA, E. R. (2014): "La relación argumentación-(des)cortesía en el discurso persuasivo", SOPRAG, 2, 2, pp. 223-261.

ANSCOMBRE, J. C. \& DUCROT, O. (1983): L'argumentation dans la langue, Bruxelles: Mardaga.

ANSCOMBRE, J. C. et al. (éds.) (2013): Opérateurs discursifs du français. Eléments de description sémantique et pragmatique, Berne: Peter Lang.

ANSCOMBRE, J. C. et al. (éds.) (2018): Opérateurs discursifs du français, 2. Eléments de description sémantique et pragmatique, Berne: Peter Lang.

BATTANER ARIAS, P. (2001): Lema: diccionario de la lengua española, Barcelona: Spes. [LEMA]

BLAS ARROYO, J. L. (2001): "No diga chorradas... La descortesía en el debate político cara a cara. Una aproximación pragma-variacionista", Oralia. Análisis del discurso oral, 4, pp. 9-45.

BRAVO, D. (ed.) (2005): Estudios de la (des)cortesía en español. Categorías conceptuales y aplicaciones a corpora orales $y$ escritos, Buenos Aires: Editorial Dunken.

BRENES PEÑA, E. (2014): "La imagen del político en los medios de comunicación. Identificación $\mathrm{y}$ análisis de las estrategias (des)corteses utilizadas en la entrevista televisiva no acomodaticia", Revista de filología, 32, pp. 63-80.

BRIZ, A. (2009): "Notas para el estudio de la relación entre las partículas discursivas y la atenuación", Bernal, M. y Hernández Flores, N., Estudios sobre lengua, sociedad y cultura. Homenaje a Diana Bravo, Stockholms: Stockholms Universitet, pp. 67-77.

BRIZ, A. et al. (coords.) (2008): Diccionario de particulas discursivas del español. Disponible en: http://www.dpde.es/ (Fecha de consulta: 05/10/2018).

BROWN, P. \& LEVINSON, S. C. (1987): Politeness. Some Universals in Language Use, Cambridge: Cambridge University Press.

CADIOT, A. et al. (1985): "Enfin, opérateur métalinguistique", Journal of Pragmatics, 9, pp. 199-239.

DÍAZ PÉREZ, J. C. (2014): "Creatividad léxica y descortesía en los medios de comunicación virtual", Revista de filología, 32, pp. 81-97.

DONAIRE, M. L. (2006): "Les dialogues intérieurs à la langue", Le Français Moderne, 74, 1, pp. 61-73.

DONAIRE, M. L. (2012): "Un point de vue polyphonique sur le point de vue", Anscombre, J. C. et al. (éds.), Voix et marqueurs du discours : des connecteurs à l'argument d'autorité, Lyon: ENS Éditions, pp. 17-30. 
DONAIRE, M. L. (2013a): “Enfin, quelle(s) stratégie(s) énonciative(s)?", Revue de Sémantique et Pragmatique, 3334, pp. 139-158.

DONAIRE, M. L. (2013b): "Entité lexicale : enfin", Anscombre, J. C. et al. (éds.) (2013): Opérateurs discursifs $d u$ français. Eléments de description sémantique et pragmatique, Berne: Peter Lang, pp. 105-119.

FLORES TREVIÑO, M. E. e INFANTE BONFIGLIO, J. M. (2014): “Descortesia-imagen y performance en el discurso político", La (des)cortesia en el discurso. Perspectivas interdisciplinarias (imagen, actos de habla y atenuación), Monterrey-Estocolmo: UANL, Programa EDICE, pp. 53-84.

FUENTES RODRÍGUEZ, C. (1991): "Adverbios de modalidad", Verba, 18, pp. 275-321.

FUENTES RODRÍGUEZ, C. (2009a): Diccionario de conectores y operadores del español, Madrid: Arco/Libros.

FUENTES RODRÍGUEZ, C. (2009b): "La argumentación en la lengua y la cortesía verbal, ¿dos teorías distintas?", Casas, M. y Márquez, R. (eds.), XI Jornadas de Lingüística, Cádiz: Publicaciones Universidad Cádiz, pp. 109-148.

FUENTES RODRÍGUEZ, C. (2010a): La gramática de la cortesía en español/LE, Madrid: Arco/Libros.

FUENTES RODRÍGUEZ, C. (2010b): "Ideología e Imagen: la ocultación en la prensa de la violencia social o lo políticamente correcto", Discurso y Sociedad, 4, 4, pp. 853-892.

FUENTES RODRÍGUEZ, C. (2011): “(Des)cortesía y violencia verbal: implicaciones lingüísticas y sociales", Fuentes Rodríguez, C. et al., Aproximaciones a la (des)cortesía verbal en español, Berne: Peter Lang, pp. 27-74.

FUENTES RODRÍGUEZ, C. (2012): "Subjetividad, argumentación y (des)cortesía”, Círculo de Lingüistica Aplicada a la Comunicación, 49, pp. 49- 92.

FUENTES RODRÍGUEZ, C. (2013a): "Argumentación, (des)cortesía y género en el discurso parlamentario", Tonos digital. Revista electrónica de estudios filológicos. Número XXV. Disponible en: https://digitum.um.es/xmlui/bitstream/1 0201/38088/1/Argumentaci\%c3\%b3n,\%20(Des)cortesia\%20y\%20g\%c3\%a9nero\%20 en $\% 20$ el\%20discurso\%20parlamentario.pdf (Fecha de consulta: 05/07/2018).

FUENTES RODRÍGUEZ, C. (2013b): "Identidad e imagen social", Imagen social y medios de comunicación, Madrid: Arco/Libros, pp. 13-24.

FUENTES RODRÍGUEZ, C. (2014): "Salvados por la cortesía estratégica", Revista de filología, 32, pp. 99-124.

FUENTES RODRÍGUEZ, C. (ed.): (2016): Estrategias argumentativas y discurso politico, Madrid: Arco/Libros.

FUENTES RODRÍGUEZ, C. (2017): "El Proyecto I+D+I MEsA: Macrosintaxis del español actual. El enunciado: estructura y relaciones", Lingüistica en la Red. Número XIV. Disponible en: http://linred.com (Fecha de consulta: 21/09/2018).

FUENTES RODRÍGUEZ, C. (2017[2000]): Lingüística pragmática y análisis del Discurso, Madrid: Arco/Libros. 
GOFFMAN, E. (1967): Interaction ritual. Essays on face-to-face behavior, New York: Chicago Linguistic Society.

GONZÁLEZ SANZ, M. (2014). Tertulia politica y (des)cortesía verbal, Sevilla: Universidad de Sevilla. Disponible en: https://idus.us.es/xmlui/bitst ream/handle/11441/24302/T .D._PROV23.pdf?sequence $=1 \&$ isAllowed $=y \quad($ Fecha de consulta: 21/09/2018).

HAVERKATE, H. (1987): "La cortesía verbal como estrategia conversacional", Diálogos Hispánicos de Ámsterdam, 6, pp. 27-63.

KAUL DE MARLANGEON, S. (2017): "Tipos de descortesía verbal y emociones en contextos de cultura hispanohablante", Pragmática sociocultural, 5, pp.1-23.

KAUL DE MARLANGEON, S. \& CORDISCO, A. (2014): "La descortesía verbal en el contexto político-ideológico de las redes sociales", Revista de filología, 32, pp. 145-162.

KIENPOINTNER, M. (2008): "Cortesía, emoción y argumentación", Briz, A. et al. (eds.), Cortesia y conversación: de lo escrito a lo oral, Valencia, Stockholms: Universidad de Valencia, Programa EDICE, pp. 25-52.

LANDONE, E. (2009): Los marcadores del discurso y cortesía verbal en español, Berne: Peter Lang.

LLAMAS SAÍZ, C. (ed.) (2018): El análisis del discurso politico: géneros y metodologías, Pamplona: EUNSA.

MANCEDA RUEDA, A. (2014): "Cortesía en 140 caracteres: interacciones en twitter entre periodistas y prosumidores", Revista de filologia, 32, pp. 163-180.

MARTÍN ZORRAQUINO, M. A. (2001): "Marcadores del discurso y estrategias de cortesía verbal en español", Montoya Ramírez, M.
I. (ed.), La lengua española y su enseñanza. Actas de las VI Jornadas sobre la enseñanza de la lengua española, Granada: Universidad de Granada, pp. 5574.

MARTÍN ZORRAQUINO, M. A. (2010): "Los marcadores del discurso y su morfologia", Loureda Lamas, O. y Acín Villa, E. (eds.), Los estudios sobre los marcadores del discurso, hoy, Madrid: Arco/Libros, pp. 92-180.

MELÉNDEZ QUERO, C. (2009): Contribución al estudio de los adverbios disjuntos de valoración afectivo-emotiva en español actual, Zaragoza: Universidad de Zaragoza. Disponible en: http://zaguan.unizar.es/record/2055 (Fecha de consulta: 05/10/2018).

MOLINER, M. (1966): Diccionario de uso del español, Madrid: Gredos, 2 vols. [DUE].

MURILLO ORNAT, S. (2010): "Los marcadores del discurso y su semántica", Loureda Lamas, O. y Acín Villa, E. (eds.), Los estudios sobre los marcadores del discurso, hoy, Madrid: Arco/Libros, pp. 241-280.

PADILLA HERRADA, M. S. (2015): "La argumentación política en Twitter", Discurso \& Sociedad, 9, 4, pp. 419-444.

PADILLA HERRADA, M. S. (2016): "Marcadores y partículas discursivas interactivas en el entorno politico/periodístico de twitter", Philologia hispalensis, 30, 1-2, pp. 193-212.

PADILLA HERRADA, M. S. (2017): "Formas de expresión de la modalidad confirmativa en WhatsApp", Pragmalingüistica, 25, pp. 439-466.

PÉREZ BÉJAR, V. et al. (2017): Corpus MEsA. Guía. Disponible en: http:/ / grupo.us.es/gru- 
poapl/acceso/actividades/pdf/gunacorpusmesa.pdf (Fecha de consulta: 13/02/2018).

PORTOLÉS, J. (2004): Pragmática para hispanistas, Madrid: Síntesis.

PROYECTO MEsA (2017): Corpus MEsA. Disponible en: http://grupo.us.es /grupoapl/otrosapartados.php?otro $=10$ (Fecha de consulta: 05/02/2018). [MEsA]

REAL ACADEMIA ESPAÑOLA (2014): Diccionario de la lengua espanola, Madrid: Espasa Calpe, $23^{a}$ edición. [DRAE]

REAL ACADEMIA ESPAÑOLA (2018a): Banco de datos (CORPES XXI). Corpus del Español del Siglo XXI. http:/ /web.frl.es/COR$\mathrm{PES} /$ view/inicioExterno.view (Fecha de consulta: 25/09/2018). [CORPES XXI]

REAL ACADEMIA ESPAÑOLA (2018b): Banco de datos (CREA). Corpus de Referencia del Español Actual. Disponible en: http://corpus.rae.es/creanet.html (Fecha de consulta: 05/08/2018). [CREA]

SANTOS RÍO, L. (2003): Diccionario de particulas, Salamanca: Luso Española de Ediciones.

SECO, M. et al. (1999): Diccionario del español actual, Madrid: Aguilar, 2 vols. [DEA]

VÁZQUEZ MOLINA, J. (coord.) (2016): Des connecteurs argumentatifs aux opérateurs discursifs, Scolia, 30. 